\title{
Early mRNA Expression of Neuroendocrine Differentiation Signals Predicts Recurrence After Radical Prostatectomy: A Transcriptomic Analysis
}

\author{
Panagiotis J. Vlachostergios ${ }^{\mathrm{a}, \mathrm{d}}$, Athanasios Karathanasis ${ }^{\mathrm{b}}$, \\ Christos N. Papandreou ${ }^{\mathrm{c}}$, Vassilios Tzortzis ${ }^{\mathrm{b}}$
}

\begin{abstract}
Background: Neuroendocrine differentiation (NED) of prostate cancer $(\mathrm{PC})$ is a process that often occurs under evolutionary pressure from pharmacologic blockade of androgen receptor signaling at advanced stages of the disease. Identifying a subset of early PC that has a higher likelihood to evolve into this entity is key for developing therapeutic strategies that could more effectively target this phenotype. This study aimed to assess the prognostic relevance of mRNA expression of major players involved in NED of primary prostate tumors.
\end{abstract}

Methods: RNA sequencing data from 122 patients with localized PC were analyzed. Transcript levels of key genes involved in NED, with a focus on endothelin axis and nuclear factor kappa B (NF- $\mathrm{B}$ ), were assessed and were correlated with time to prostate specific antigen (PSA) recurrence. Copy number alteration of tumor suppressor genes and gene expression of additional signals hallmarking NED was compared between altered and unaltered groups, including lineage determining transcription factors, transcriptional repressors, cell cycle and epigenetic regulators.

Results: The presence of altered mRNA expression using a z-score threshold of 2 in NFKB1, RELA, EDN1, EDNRA, and EDNRB genes was associated with a higher Gleason score $(P<0.001)$ and a shorter time to biochemical recurrence $(B C R)(P=0.029)$. There was a significant direct correlation between NFKB1 and RELA (P $<0.001)$, NFKB1 and EDNRA $(\mathrm{P}<0.001)$, NFKB1 and EDNRB

Manuscript submitted October 3, 2021, accepted November 30, 2021

Published online December 8, 2021

aDivision of Hematology and Medical Oncology, Department of Medicine, Weill Cornell Medicine, New York, NY 10065, USA

${ }^{b}$ Department of Urology, University of Thessaly School of Health Sciences Faculty of Medicine, University Hospital of Larissa, Larissa 41100, Greece 'Department of Medical Oncology, Faculty of Medicine Papageorgiou Hospital, Aristotle University of Thessaloniki, School of Health Sciences, Thessaloniki 54124, Greece

${ }^{\mathrm{d} C o r r e s p o n d i n g ~ A u t h o r: ~ P a n a g i o t i s ~ J . ~ V l a c h o s t e r g i o s, ~ D i v i s i o n ~ o f ~ H e m a t o l-~}$ ogy and Medical Oncology, Department of Medicine, Weill Cornell Medicine, New York, NY 10065, USA. Email: pjv9003@med.cornell.edu

doi: https://doi.org/10.14740/wjon1423
$(\mathrm{P}<0.001)$, EDNRA and EDNRB expression $(\mathrm{P}<0.001)$. ASCL1 $(\mathrm{q}<0.001)$, ONECUT2 $(\mathrm{q}<0.001)$, DLL3 $(\mathrm{q}=0.019)$, AURKA $(\mathrm{q}$ $=0.013)$, AURKB $(q=0.014)$, PLK1 $(q<0.001)$, and EZH2 $(q<$ $0.001)$ were enriched in patients with tumors harboring alterations in endothelin axis and NF- $\kappa \mathrm{B}$ subunit genes whereas REST was downregulated $(\mathrm{q}<0.001)$.

Conclusions: This analysis suggests that altered mRNA expression of NF- $\kappa \mathrm{B}$ and endothelin axis genes in early PC is not only a harbinger of a more aggressive clinical course but is also associated with aberrant gene expression of several transcription factors, transcriptional repressors, cell cycle and epigenetic regulators that are directly involved in NED, in line with their biological roles. This may have implications for closer follow-up and potential use of targeted therapeutic approaches postoperatively in the adjuvant setting to improve outcomes of these patients.

Keywords: Neuroendocrine differentiation; Prostate cancer; Radical prostatectomy; PSA recurrence; Endothelin; Nuclear factor kappa B; RNA sequencing; mRNA expression

\section{Introduction}

Neuroendocrine differentiation (NED) of prostate cancer (PC) represents a state of transformation from luminal to small cell morphology $[1,2]$. This transition is of particular clinical significance as it results in a resistant phenotype that does not respond to therapies targeting androgen receptor signaling [3]. Several acquired gene alterations affecting NED mediators and signals are implicated in this process, including loss of tumor suppressors PTEN, RB1, TP53 [4, 5], abundance of master transcriptional regulators (ASCL1, ONECUT2) and mediators (DLL3) determining lineage plasticity towards a neuronal phenotype [6-8], cell cycle genes (AURKA, AURKB, PLK1) [9-11], transcriptional repressors (REST) [12] and epigenetic modifiers involved in histone methylation and gene repression (EZH2) $[13,14]$.

Nuclear factor kappa B (NF- $\mathrm{kB})$ is a key transcription factor with known tumor-promoting and anti-apoptotic effects in various primaries. NF- $\mathrm{kB}$ consists of a heterodimer formed by the p50 and RelA (p65) proteins, which are encoded by the 
NFKB1 and RELA genes, respectively [15]. NF- $\kappa B$ is constitutively active in advanced PC leading to increased angiogenesis, invasion and metastasis [16, 17]. More importantly, NF$\kappa \mathrm{B}$ activation is sufficient to maintain androgen-independent growth of $\mathrm{PC}$ by regulating androgen receptor (AR) action [18].

Endothelin-1 (ET-1) is a key neuropeptide, signaling through its receptors, endothelin receptor A (ETA) and B (ETB) to mitigate proliferative signals to PC cells [19]. High immunohistochemical expression of ET-1 and ETA is associated with aggressive features of PC and is frequently found in high Gleason tumors, extracapsular disease and metastases $[20,21]$. We have previously shown that ET-1 is mechanistically linked with NF- $\kappa$ B activation, nuclear translocation and oncogenic signaling to promote androgen-independent growth $[22,23]$.

Because most genomic alterations characterizing the NE phenotype are not present in early PC, we aimed to assess the clinical relevance of mRNA expression of NF- $\kappa B$ and endothelin axis-encoding genes in primary prostate tumors with regard to biochemical recurrence (BCR), and whether this could be associated with early transcriptomic changes of genes that function as NED inducers at later stages.

\section{Materials and Methods}

\section{Subjects}

This study used a publicly available database, cBioportal for Cancer Genomics (www.cbioportal.org) with DNA and RNA sequencing data from 218 tumor samples (181 primaries, 37 metastases) and 149 matched normal samples obtained from patients treated by radical prostatectomy (RP) at Memorial Sloan-Kettering Cancer Center, USA [24]. Of those, 122 treatment-naive patients underwent RP, and were subsequently followed with history, physical exam, and serum prostate specific antigen (PSA) testing every 3 months for the first year, 6 months for the second year, and annually thereafter [24]. For all analyses, BCR was defined as PSA $\geq 0.2 \mathrm{ng} / \mathrm{mL}$ on two occasions [24].

\section{Ethical issues and informed consent}

This study represents an analysis of publicly available data from a study conducted under Memorial Sloan-Kettering Cancer Center Institutional Review Board approval [24], and is in compliance with the ethical standards of the responsible institution on human subjects as well as with the Helsinki Declaration. Informed consent was obtained from all subjects with publicly available data [24] involved in this study.

\section{Experimental procedure}

DNA and RNA were extracted from dissected tissue containing greater than $70 \%$ tumor cell content [24]. DNA and RNA
Table 1. Clinical Characteristics of the Study Cohort $(N=122)$

\begin{tabular}{|cl|}
\hline & $\mathbf{N}(\%)$ \\
\hline Gleason score & \\
6 & $27(22.1)$ \\
7 & $64(52.4)$ \\
8 & $10(8.2)$ \\
9 & $10(8.2)$ \\
\hline T stage & \\
T1 & $63(51.6)$ \\
T2 & $47(38.5)$ \\
T3 & $6(4.9)$ \\
T4 & $1(0.8)$ \\
\hline
\end{tabular}

were hybridized to Agilent $244 \mathrm{~K}$ array comparative genomic hybridization (aCGH) microarrays, Affymetrix Human Exon 1.0 ST arrays, and/or Agilent microRNA V2 arrays, respectively [24]. A total of 251 million bases in coding exons and adjacent intronic sequences of 138 cancer-related genes in 91 samples were polymerase chain reaction (PCR)-amplified and sequenced by Sanger capillary sequencing [24]. Ninety-five sites of known mutation in 22 genes were also genotyped using the iPLEX Sequenom platform [24]. Outlier profiles for all transcripts and outlier assignments in all tumors were determined from normalized expression data [24]. A z score threshold of \pm 2 was used for comparison of mRNA expression between tumor and normal prostate samples.

\section{Statistics}

The Kaplan Meier method was used to assess the association between altered and unaltered mRNA expression levels with BCR-free survival. The two-sided $t$-test was used to assess for correlations between mRNA expression of different genes. The Chi-squared and Kruskal-Wallis tests were used to assess correlations between mRNA expression of genes and clinical characteristics. The Benjamin-Hochberg false discovery rate (FDR) correction procedure was used for multiple comparisons. All results were reported at the 0.05 significance level.

\section{Results}

A total of 122 samples from corresponding patients with available mRNA profiling were included in this study. More than half patients $(n=64$ or $52.4 \%)$ had a Gleason score of 7 (Table $1)$. The majority of patients $(n=110)$ had disease confined to the prostate, either T1 $(n=63$ or $51.6 \%)$ or T2 $(n=47$ or $38.5 \%$ ) stage (Table 1).

Queried genes were altered in 69 (55\%) of patients/samples. The most commonly altered gene expression was that of EDNRA (41\%), followed by RELA (16\%), NFKB1 (15\%), EDNRB (6\%), and EDN1 (5\%) (Fig. 1). The presence of mRNA expression alterations was more frequent $(\mathrm{P}<0.001)$ 


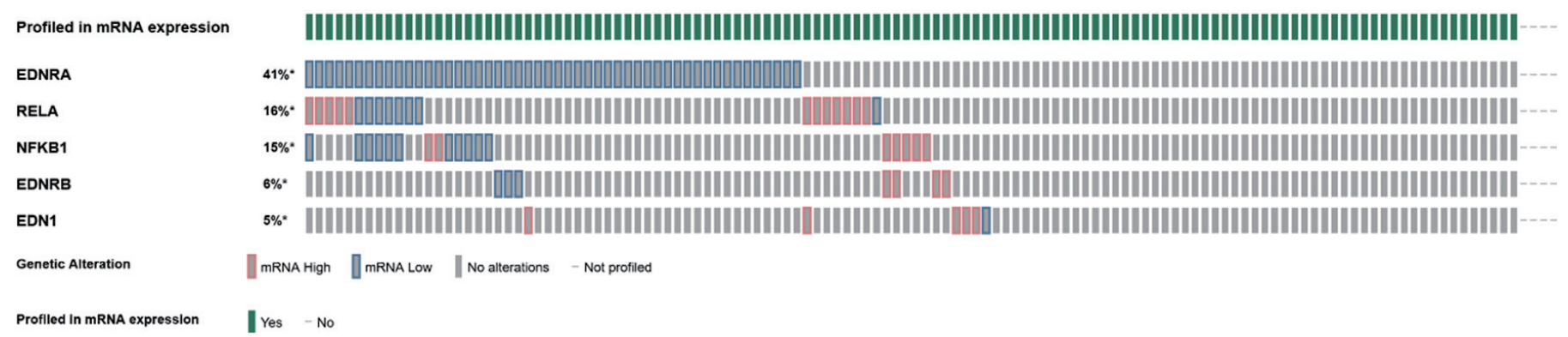

Figure 1. Oncoplot of mRNA expression (high, low, no alterations) among endothelin axis and NF-KB subunit genes.

in tumors with higher Gleason score, particularly Gleason 8 (10/10 or $100 \%$ altered) and Gleason 9 (8/10 or $80 \%$ altered), while there was more equal distribution between altered and unaltered tumors within Gleason 6 (13/27 or $48.1 \%$ altered) and Gleason 7 (37/64 or 57.8\% altered) scores (Fig. 2).

There were significant direct correlations of mRNA expression between NFKB1 and RELA (Fig. 3a), NFKB1 and EDNRA (Fig. 3b), NFKB1 and EDNRB (Fig. 3c), EDNRA and EDNRB genes (Fig. 3d). Thirty-two (26.2\%) patients recurred during follow-up while 80 patients remained diseasefree $(65.6 \%)$. Patients with tumors harboring mRNA expression alterations in the tested genes experienced a significantly shorter BCR-free survival (log-rank $\mathrm{P}=0.029$ ) (Fig. 4).

Because most typical molecular features of the NE phenotype are not present in early PC, we tested whether the subset of patients with tumors harboring altered NF- $\kappa B$ and endothelin axis genes could be enriched in early genomic and transcriptomic changes that are etiologically related with NEPC, including tumor suppressors PTEN, RB1, TP53, master transcriptional regulators ASCL1, ONECUT2, REST, and DLL3 determining lineage plasticity towards a neuronal phenotype, cell cycle genes AURKA, AURKB, PLK1 and epigenetic modifier EZH2 which is involved in histone methylation and gene repression [4-14].

First, we found that a higher number of tumors with altered $\mathrm{NF}-\kappa \mathrm{B}$ and endothelin axis gene expression displayed copy number losses of the tumor suppressors RB1 (7.2\% vs. 1.7\%), TP53 (2.9\% vs. 1.7\%) and PTEN (14.5\% vs. 7.0\%), compared to those without NF- $\mathrm{B}$ and endothelin axis gene alterations (Table 2, Fig. 5). Second, mRNA expression of ASCL1 (log ra- tio $=0.88 ; \mathrm{q}<0.001)$, ONECUT2 $(\log$ ratio $=0.93 ; \mathrm{q}<0.001)$, DLL3 $(\log$ ratio $=0.58 ; \mathrm{q}=0.019)$, AURKA $(\log$ ratio $=0.94$; $q=0.013)$, AURKB $(\log$ ratio $=0.53 ; \mathrm{q}=0.014)$, PLK1 $(\log$ ratio $=1.08 ; \mathrm{q}<0.001)$, and $\mathrm{EZH} 2(\log$ ratio $=1.87 ; \mathrm{q}<0.001)$ were enriched in patients with tumors harboring alterations in endothelin axis and NF- $\mathrm{BB}$ subunit genes whereas transcriptional repressor REST was downregulated $(\log$ ratio $=-0.86 ; \mathrm{q}$ $<0.001$ ) (Fig. 6).

\section{Discussion}

In this study we assessed the transcriptional expression, interrelations and clinical significance of major NED pathways in patients with primary PC undergoing RP. We demonstrate that changes in mRNA levels of NFKB1, RELA, EDN1, EDNRA, and EDNRB are interrelated and are associated with Gleason score and BCR after RP. These results are consistent with immunohistochemical expression findings from other groups and ours, who reported that ET- 1 and NF- $\kappa$ B protein staining in primary prostate tumors predicts aggressiveness of $\mathrm{PC}$ with regard to grade and stage, as well as with risk of BCR [25-32]. Thus, our findings complement our prior work and provide a comprehensive understanding of the prognostic value of key members of the endothelin axis and NF- $\mathrm{kB}$ subunits both at the transcriptional and protein expression levels.

Taking a step further, our study strengthens the role of NF$\kappa \mathrm{B}$ and endothelin axis genes as early predictors of NED in primary PC by providing evidence of direct association with known NED mediators and signals implicated in this process,

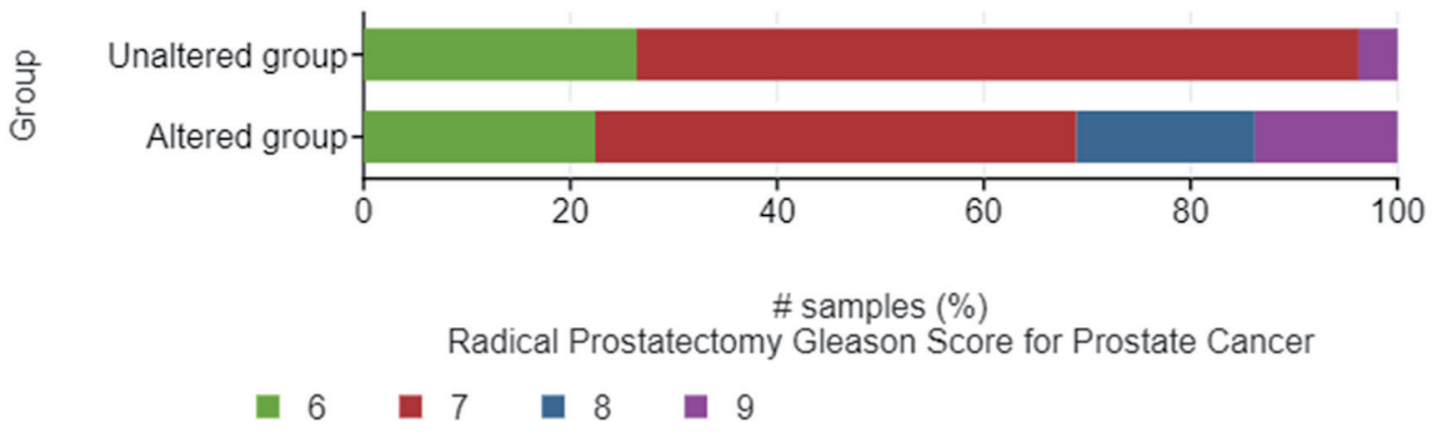

Figure 2. Bar graphs of the distribution between altered and unaltered groups of patients within different Gleason scores. 


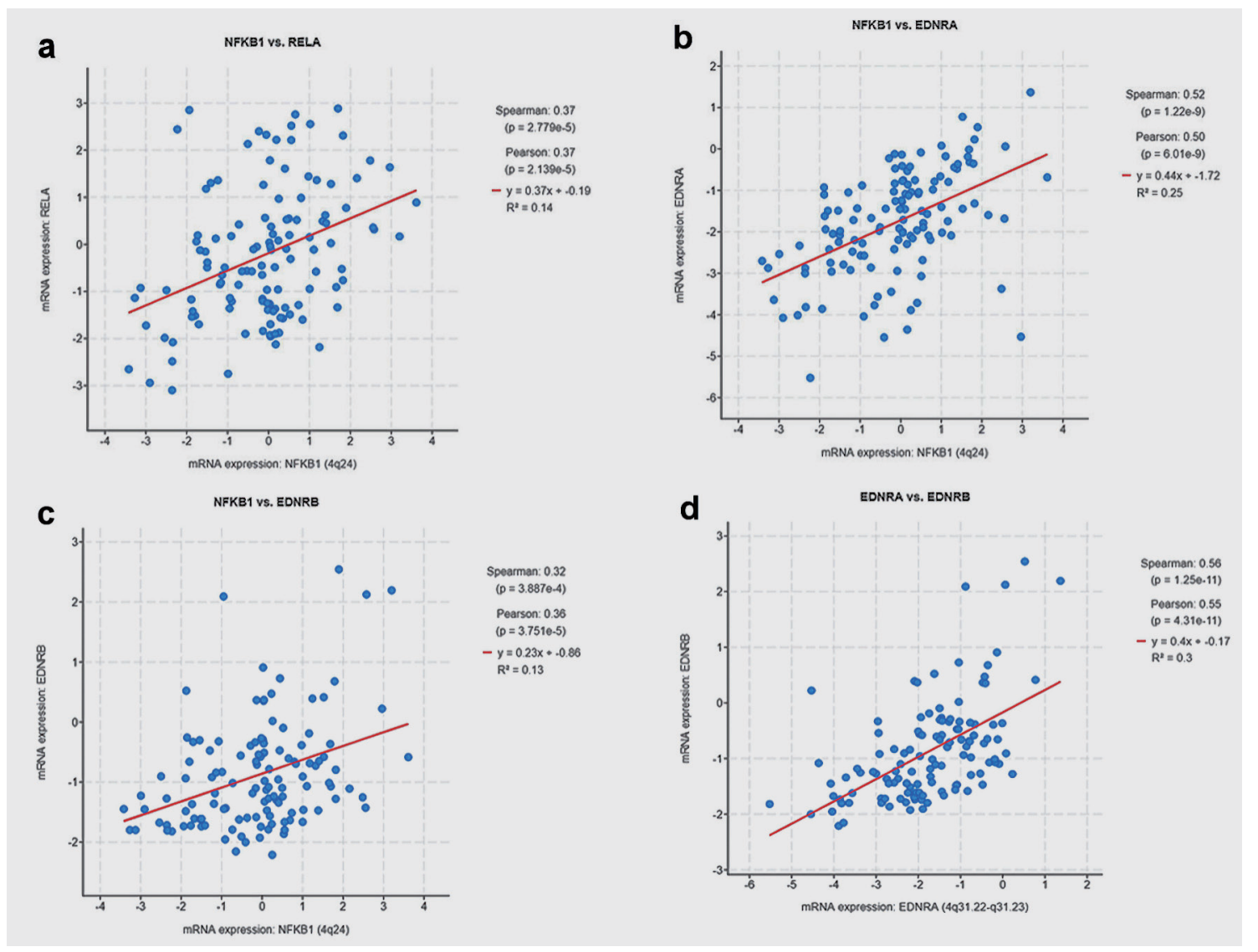

Figure 3. Scatter plots depicting the correlation of mRNA expression between: (a) NFKB1 and RELA, (b) NFKB1 and EDNRA, (c) NFKB1 and EDNRB, (d) EDNRA and EDNRB genes.

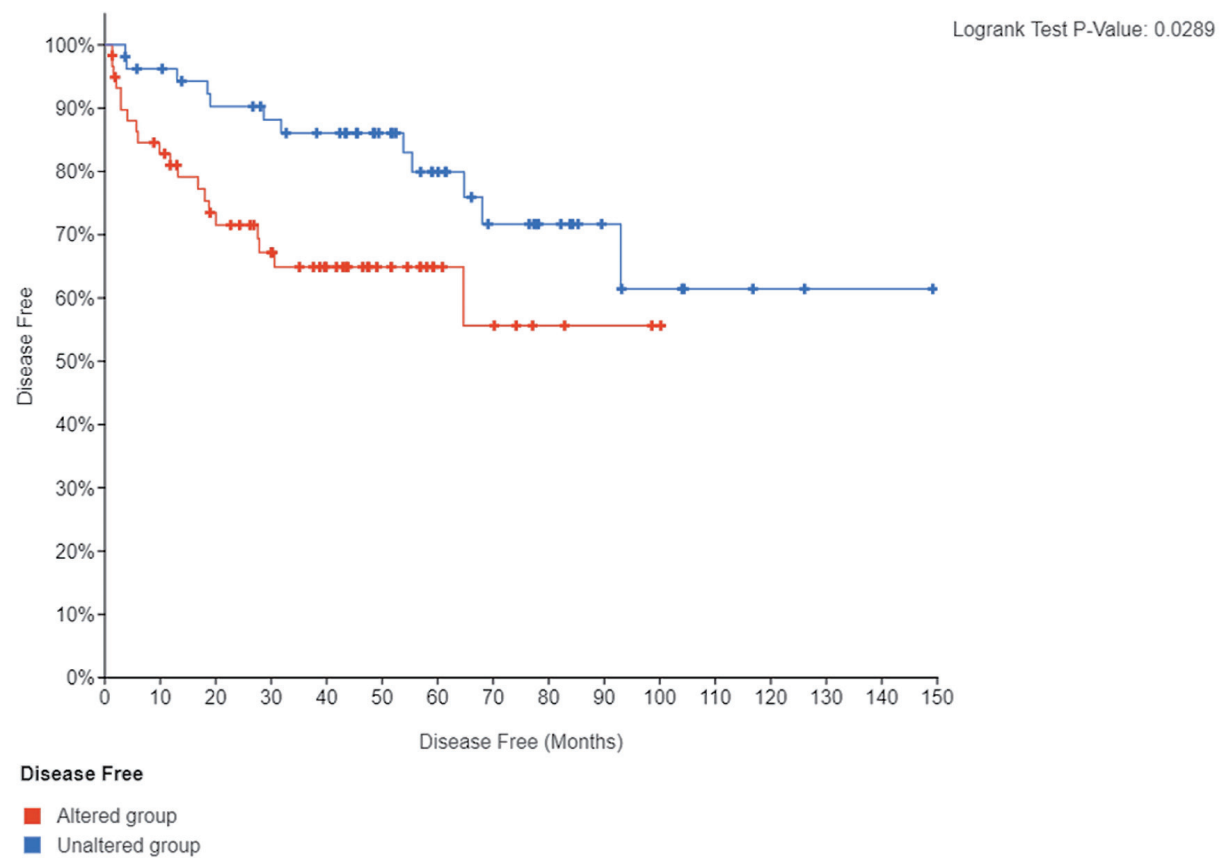

Figure 4. Kaplan Meier curve of BCR-free (disease-free) survival according to presence or absence of mRNA expression alterations in endothelin axis and NF-KB subunit genes. BCR: biochemical recurrence. 
Table 2. Copy Number Loss in Tumor Suppressor Genes Between Endothelin Axis and NF-kB Altered and Unaltered Groups

\begin{tabular}{|c|c|c|c|}
\hline Genes and group & $\mathbf{N}(\%)$ & P value & $q$ value \\
\hline \multicolumn{4}{|l|}{ PTEN } \\
\hline Altered & $10 / 69(14.49)$ & 0.148 & 0.598 \\
\hline Unaltered & $4 / 57(7.02)$ & & \\
\hline \multicolumn{4}{|l|}{$\mathrm{RB} 1$} \\
\hline Altered & $5 / 69(7.25)$ & 0.154 & 0.598 \\
\hline Unaltered & $1 / 57(1.75)$ & & \\
\hline \multicolumn{4}{|l|}{ TP53 } \\
\hline Altered & $2 / 69(2.90)$ & 0.572 & 0.600 \\
\hline Unaltered & $1 / 57(1.75)$ & & \\
\hline
\end{tabular}

including tumor suppressors (PTEN, RB1, TP53), master transcriptional regulators (ASCL1, ONECUT2, REST) and mediators (DLL3) determining lineage plasticity towards a neuronal phenotype, cell cycle genes (AURKA, AURKB, PLK1), and epigenetic modifiers involved in histone methylation and gene repression (EZH2) [4-14].

Our findings suggest that altered NFKB1, RELA, EDN1, EDNRA, and EDNRB genes in primary prostate tumors could serve as surrogates of early NED through acquisition of early genomic and transcriptomic changes in NED hallmark genes. Previous studies have emphasized that low PSA, high-grade $\mathrm{PC}$ of Gleason 8 - 10 has very high risk for PCspecific mortality, potentially responds poorly to androgen deprivation therapy, and is associated with neuroendocrine genomic features [33]. This becomes even more important in our study given that the majority of tumors were Gleason $\leq$ 7 and only $16 \%$ of tumors were Gleason 8 or 9 ; yet we were still able to detect preliminary transcriptomic changes associated with NED that led to a shorter time to BCR. Hence, while NED is a well-described phase in the continuum of

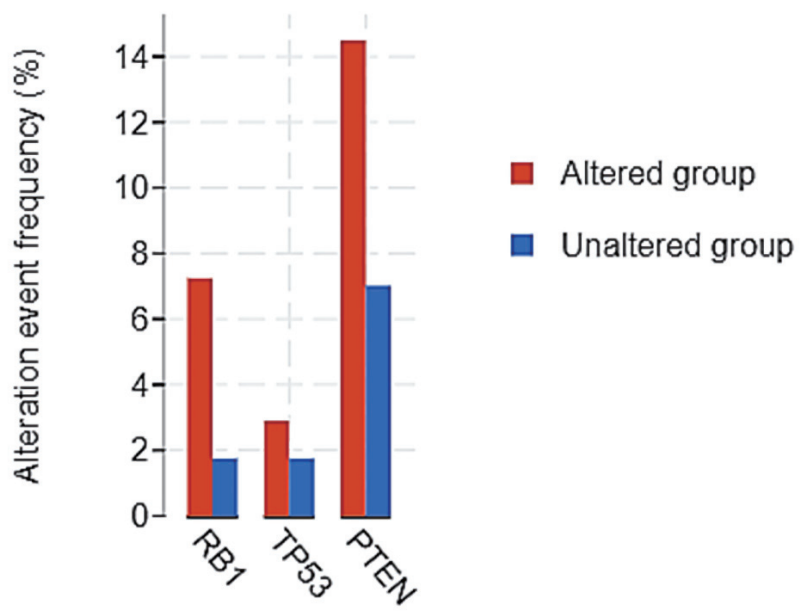

Figure 5. Copy number loss in tumor suppressor genes between endothelin axis/NF-kB altered and unaltered groups.
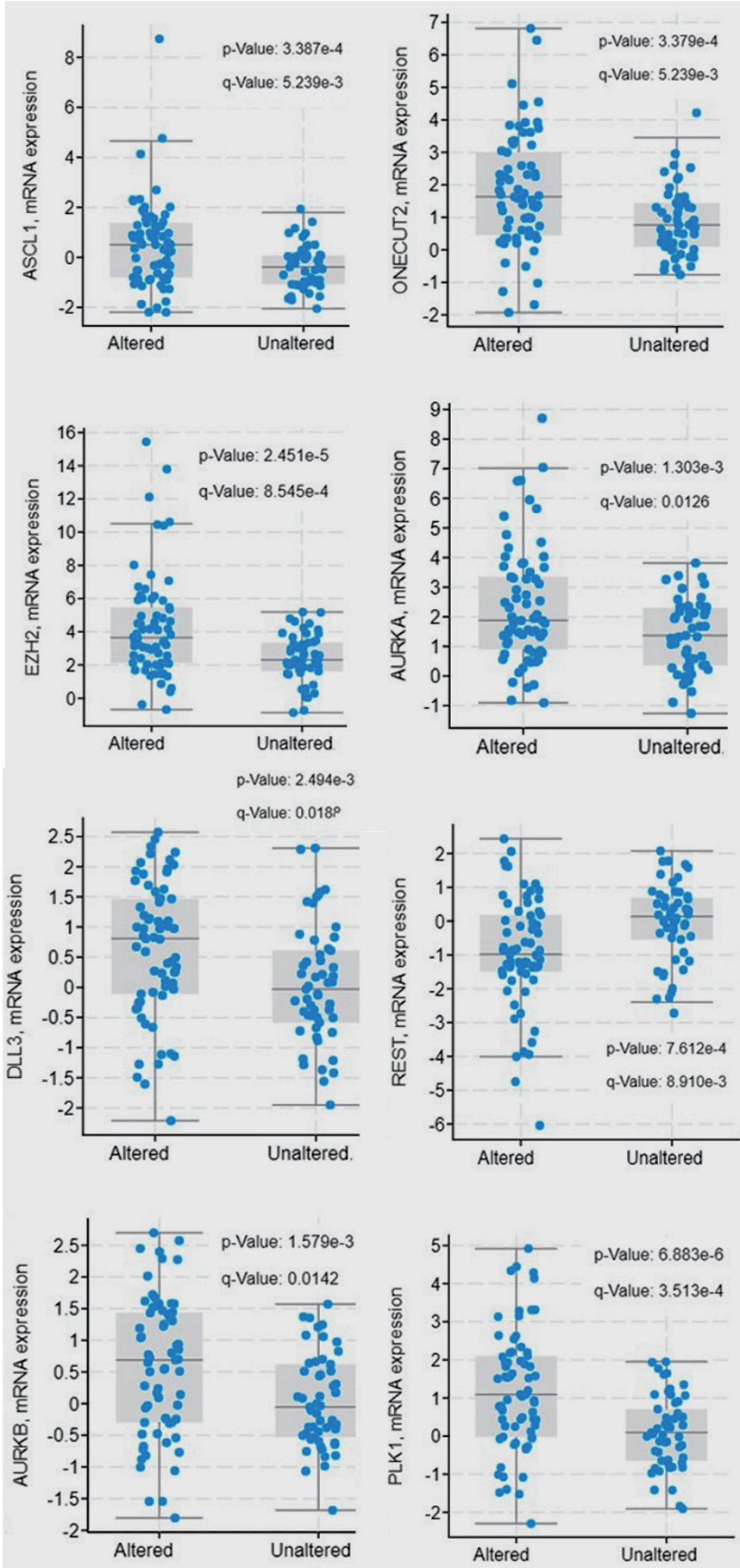

Figure 6. Gene expression of neuroendocrine differentiation signals between endothelin axis and NF-KB altered and unaltered groups.

advanced $\mathrm{PC}$, predicting transition to this state at an early stage while PC remains curable opens new avenues for early therapeutic targeting of this resistant phenotype. The type of definitive local therapy (RP vs. radiation) itself might result in different outcomes of these patients, according to a Surveillance, Epidemiology, and End Results (SEER) database analysis of 309 de novo NEPC cases, in whom RP improved 
overall survival (OS) among individuals with non-metastatic disease, whereas radiation therapy did not affect OS rates [34]. Additionally, considering the impact of different surgical approaches on quality of life after treatment in this subset of patients with aggressive disease, it might be reasonable to favor a robotic-assisted RP which has been associated with higher 12-month urinary function and 6-month sexual function propensity scores compared to laparoscopic and open $\mathrm{RP}$, respectively [35].

The present study is limited by the relatively small number of patients included; however, the fact that an external prospective PC cohort was analyzed adds more value to our prior observations at the protein expression level of endothelin axis and NF- $\kappa$ B pathway. Further, high Gleason score $(\geq 8)$ tumors were a minority in this study which explains the small number of patients who experienced BCR during this study's long follow-up of up to 150 months. It may be postulated that if the study had included more high-risk PC patients, the mRNA expression levels of endothelin axis and NF- $\kappa B$ subunit genes as well as the enrichment in NED genomic and transcriptomic signatures would be more pronounced.

\section{Conclusions}

Collectively, this study supports the clinical significance of endothelin axis and NF- $\kappa$ B subunits mRNA expression in early $\mathrm{PC}$ as surrogates of BCR and of a typical NED transcriptomic profile. It also poses implications for therapeutic targeting against key members of these pathways. ETA antagonists, including atrasentan and zibotentan have been tested previously in patients with advanced, castration-resistant PC, unfortunately without success $[36,37]$. Given the association of endothelin axis genes with targetable NED markers, pharmacologic inhibition of AURKA, DLL3 or EZH2 which is already being investigated in the advanced castration-resistant setting [3840] might be worth testing at an early stage.

\section{Acknowledgments}

None to declare.

\section{Financial Disclosure}

This research received no external funding.

\section{Conflict of Interest}

The authors declare no conflict of interest.

\section{Informed Consent}

Informed consent was obtained from all subjects with publicly available data involved in this study.

\section{Author Contributions}

PJV conceptualized and designed the study, performed the analysis, interpreted the results and wrote the manuscript. AK, $\mathrm{CNP}$, and VT contributed in the interpretation of the results, and writing of the manuscript. All authors reviewed and approved the final manuscript.

\section{Data Availability}

Publicly available data supporting results of this study were previously deposited in NCBI GEO under accession number GSE21032 [24] and can be accessed through the cBioPortal for Cancer Genomics at cbioportal.org.

\section{References}

1. Vlachostergios PJ, Papandreou CN. Targeting neuroendocrine prostate cancer: molecular and clinical perspectives. Front Oncol. 2015;5:6.

2. Puca L, Vlachostergios PJ, Beltran H. Neuroendocrine differentiation in prostate cancer: emerging biology, models, and therapies. Cold Spring Harb Perspect Med. 2019;9(2):a030593.

3. Vlachostergios PJ, Puca L, Beltran H. Emerging variants of castration-resistant prostate cancer. Curr Oncol Rep. 2017;19(5):32.

4. Aparicio AM, Shen L, Tapia EL, Lu JF, Chen HC, Zhang $\mathrm{J}, \mathrm{Wu} \mathrm{G}$, et al. Combined tumor suppressor defects characterize clinically defined aggressive variant prostate cancers. Clin Cancer Res. 2016;22(6):1520-1530.

5. Abida W, Cyrta J, Heller G, Prandi D, Armenia J, Coleman I, Cieslik M, et al. Genomic correlates of clinical outcome in advanced prostate cancer. Proc Natl Acad Sci U S A. 2019;116(23):11428-11436.

6. Rapa I, Ceppi P, Bollito E, Rosas R, Cappia S, Bacillo E, Porpiglia F, et al. Human ASH1 expression in prostate cancer with neuroendocrine differentiation. Mod Pathol. 2008;21(6):700-707.

7. Guo H, Ci X, Ahmed M, Hua JT, Soares F, Lin D, Puca $\mathrm{L}$, et al. ONECUT2 is a driver of neuroendocrine prostate cancer. Nat Commun. 2019;10(1):278.

8. Puca L, Gavyert K, Sailer V, Conteduca V, Dardenne E, Sigouros M, Isse K, et al. Delta-like protein 3 expression and therapeutic targeting in neuroendocrine prostate cancer. Sci Transl Med. 2019;11(484):eaav0891.

9. Beltran H, Rickman DS, Park K, Chae SS, Sboner A, MacDonald TY, Wang Y, et al. Molecular characterization of neuroendocrine prostate cancer and identification of new drug targets. Cancer Discov. 2011;1(6):487-495.

10. Park K, Chen Z, MacDonald TY, Siddiqui J, Ye H, Erbersdobler A, Shevchuk MM, et al. Prostate cancer with Paneth cell-like neuroendocrine differentiation has recognizable histomorphology and harbors AURKA gene amplification. Hum Pathol. 2014;45(10):2136-2143.

11. Zhang Z, Hou X, Shao C, Li J, Cheng JX, Kuang S, Ah- 
$\operatorname{mad} N$, et al. Plk1 inhibition enhances the efficacy of androgen signaling blockade in castration-resistant prostate cancer. Cancer Res. 2014;74(22):6635-6647.

12. Zhang X, Coleman IM, Brown LG, True LD, Kollath L, Lucas JM, Lam HM, et al. SRRM4 Expression and the Loss of REST Activity May Promote the Emergence of the Neuroendocrine Phenotype in Castration-Resistant Prostate Cancer. Clin Cancer Res. 2015;21(20):4698-4708.

13. Ku SY, Rosario S, Wang Y, Mu P, Seshadri M, Goodrich ZW, Goodrich MM, et al. Rb1 and Trp53 cooperate to suppress prostate cancer lineage plasticity, metastasis, and antiandrogen resistance. Science. 2017;355(6320):78-83.

14. Puca L, Bareja R, Prandi D, Shaw R, Benelli M, Karthaus WR, Hess J, et al. Patient derived organoids to model rare prostate cancer phenotypes. Nat Commun. 2018;9(1):2404.

15. Perkins ND. The diverse and complex roles of NF-kappaB subunits in cancer. Nat Rev Cancer. 2012;12(2):121132.

16. Chen CD, Sawyers CL. NF-kappa B activates prostate-specific antigen expression and is upregulated in androgen-independent prostate cancer. Mol Cell Biol. 2002;22(8):2862-2870.

17. Sweeney C, Li L, Shanmugam R, Bhat-Nakshatri P, Jayaprakasan V, Baldridge LA, Gardner T, et al. Nuclear factor-kappaB is constitutively activated in prostate cancer in vitro and is overexpressed in prostatic intraepithelial neoplasia and adenocarcinoma of the prostate. Clin Cancer Res. 2004;10(16):5501-5507.

18. Jin RJ, Lho Y, Connelly L, Wang Y, Yu X, Saint Jean L, Case TC, et al. The nuclear factor-kappaB pathway controls the progression of prostate cancer to androgen-independent growth. Cancer Res. 2008;68(16):6762-6769.

19. Rosano L, Spinella F, Bagnato A. Endothelin 1 in cancer: biological implications and therapeutic opportunities. Nat Rev Cancer. 2013;13(9):637-651.

20. Menard J, Durlach A, Barbe C, Joseph K, Lorenzato M, Azemar MD, Perez T, et al. Endothelin-1: a predictor of extracapsular extension in clinically localized prostate cancer? BJU Int. 2011;108(2 Pt 2):E104-109.

21. Gohji K, Kitazawa S, Tamada H, Katsuoka Y, Nakajima M. Expression of endothelin receptor a associated with prostate cancer progression. J Urol. 2001;165(3):10331036.

22. Patrikidou A, Vlachostergios PJ, Voutsadakis IA, Hatzidaki E, Valeri RM, Destouni C, Apostolou E, et al. Inverse baseline expression pattern of the NEP/neuropeptides and NFkappaB/proteasome pathways in androgen-dependent and androgen-independent prostate cancer cells. Cancer Cell Int. 2011;11(1):13.

23. Patrikidou A, Vlachostergios PJ, Voutsadakis IA, Hatzidaki E, Valeri RM, Destouni C, Apostolou E, et al. Neuropeptide-inducible upregulation of proteasome activity precedes nuclear factor kappa B activation in androgen-independent prostate cancer cells. Cancer Cell Int. 2012;12(1):31.

24. Taylor BS, Schultz N, Hieronymus H, Gopalan A, Xiao Y, Carver BS, Arora VK, et al. Integrative genomic profiling of human prostate cancer. Cancer Cell. 2010;18(1):11-22.
25. Rosenblatt R, Valdman A, Cheng L, Lopez-Beltran A, Montironi R, Ekman P, Egevad L. Endothelin-1 expression in prostate cancer and high grade prostatic intraepithelial neoplasia. Anal Quant Cytol Histol. 2009;31(3):137-142.

26. Montironi R, Mazzucchelli R, Barbisan F, Stramazzotti D, Santinelli A, Lopez Beltran A, Cheng L, et al. Immunohistochemical expression of endothelin-1 and endothelin-A and endothelin-B receptors in high-grade prostatic intraepithelial neoplasia and prostate cancer. Eur Urol. 2007;52(6):1682-1689.

27. Fradet V, Lessard L, Begin LR, Karakiewicz P, Masson AM, Saad F. Nuclear factor-kappaB nuclear localization is predictive of biochemical recurrence in patients with positive margin prostate cancer. Clin Cancer Res. 2004;10(24):8460-8464.

28. Lessard L, Karakiewicz PI, Bellon-Gagnon P, AlamFahmy M, Ismail HA, Mes-Masson AM, Saad F. Nuclear localization of nuclear factor-kappaB p65 in primary prostate tumors is highly predictive of pelvic lymph node metastases. Clin Cancer Res. 2006;12(19):5741-5745.

29. Ross JS, Kallakury BV, Sheehan CE, Fisher HA, Kaufman RP, Jr., Kaur P, Gray K, et al. Expression of nuclear factor-kappa B and I kappa B alpha proteins in prostatic adenocarcinomas: correlation of nuclear factor-kappa $B$ immunoreactivity with disease recurrence. Clin Cancer Res. 2004;10(7):2466-2472.

30. Domingo-Domenech J, Mellado B, Ferrer B, Truan D, Codony-Servat J, Sauleda S, Alcover J, et al. Activation of nuclear factor-kappaB in human prostate carcinogenesis and association to biochemical relapse. Br J Cancer. 2005;93(11):1285-1294.

31. Grosset AA, Ouellet V, Caron C, Fragoso G, Barres V, Delvoye N, Latour M, et al. Validation of the prognostic value of NF-kappaB p65 in prostate cancer: a retrospective study using a large multi-institutional cohort of the Canadian prostate cancer biomarker network. PLoS Med. 2019;16(7):e1002847.

32. Vlachostergios PJ, Karasavvidou F, Kakkas G, Moutzouris G, Patrikidou A, Voutsadakis IA, Daliani DD, et al. Expression of neutral endopeptidase, endothelin-1, and nuclear factor kappa B in prostate cancer: interrelations and associations with prostate-specific antigen recurrence after radical prostatectomy. Prostate Cancer. 2012;2012:452795.

33. Mahal BA, Yang DD, Wang NQ, Alshalalfa M, Davicioni E, Choeurng V, Schaeffer EM, et al. Clinical and genomic characterization of low-prostate-specific antigen, highgrade prostate cancer. Eur Urol. 2018;74(2):146-154.

34. Zaffuto E, Pompe R, Zanaty M, Bondarenko HD, LeyhBannurah SR, Moschini M, Dell'Oglio P, et al. Contemporary incidence and cancer control outcomes of primary neuroendocrine prostate cancer: a seer database analysis. Clin Genitourin Cancer. 2017;15(5):e793-e800.

35. Antonelli A, Palumbo C, Noale M, Porreca A, Maggi S, Simeone C, Bassi P, et al. Impact of surgical approach on patient-reported outcomes after radical prostatectomy: a propensity score-weighted analysis from a multicenter, prospective, observational study (The Pros-IT CNR Study). Urol Int. 2019;103(1):8-18. 
36. Carducci MA, Saad F, Abrahamsson PA, Dearnaley DP, Schulman CC, North SA, Sleep DJ, et al. A phase 3 randomized controlled trial of the efficacy and safety of atrasentan in men with metastatic hormone-refractory prostate cancer. Cancer. 2007;110(9):1959-1966.

37. Nelson JB, Fizazi K, Miller K, Higano C, Moul JW, Akaza H, Morris T, et al. Phase 3, randomized, placebocontrolled study of zibotentan (ZD4054) in patients with castration-resistant prostate cancer metastatic to bone. Cancer. 2012;118(22):5709-5718.

38. Mansfield AS, Hong DS, Hann CL, Farago AF, Beltran
H, Waqar SN, Hendifar AE, et al. A phase I/II study of rovalpituzumab tesirine in delta-like 3-expressing advanced solid tumors. NPJ Precis Oncol. 2021;5(1):74.

39. Beltran H, Oromendia C, Danila DC, Montgomery B, Hoimes C, Szmulewitz RZ, Vaishampayan U, et al. A phase II trial of the aurora kinase A inhibitor alisertib for patients with castration-resistant and neuroendocrine prostate cancer: efficacy and biomarkers. Clin Cancer Res. 2019;25(1):43-51.

40. First EZH2 inhibitor approved-for rare sarcoma. Cancer Discov. 2020;10(3):333-334. 